\title{
Parenting stress of caregivers of young children who are HIV Positive
}

\author{
J Potterton', A Stewart', P Cooper² \\ Department of Physiotherapy 1 \& Department of Paediatrics², University of the Witwatersrand, Johannesburg, South Africa
}

\begin{abstract}
.
Objective: Paediatric HIV remains a major challenge in Sub-Saharan Africa. Paediatric HIV is a multi-generational disorder with far-reaching implications for the whole family. Parenting stress in caregivers of HIV infected children has been studied in developed countries but never in South Africa. The aim of this study was to determine the extent of parenting stress in caregivers of children infected with HIV in South Africa. Further objectives were to monitor the levels of stress over one year after caregivers started attending a paediatric HIV clinic and to ascertain what factors were predictive of a decrease in parenting stress over that time. Method: One hundred and twenty two caregiver and children dyads were recruited into this study. Caregivers completed the Parenting Stress Index/ Short form at baseline and after six and 12 months. Demographic information was collected and the children's heights, weights and CD4 counts were recorded at each visit. Results: The families that participated in this study came from very poor socio-economic backgrounds. Eighty five percent of the children were still being cared for by their biological mothers. The parenting stress levels of the caregivers in this study were extremely high at baseline. Although the parenting stress levels did come down significantly over the study period $(\mathrm{p}<0.001)$ they remained high and warrant further investigation and management. A better level of education, better housing facilities and fewer adults living in the household were the three most important factors predicting a decrease in parenting stress over a one year period. Conclusion: Parenting stress of caregivers of young children infected with HIV is extremely high and warrants further investigation and long term management.
\end{abstract}

Key words: Psychology, Pediatric; Care givers; Stress; Human Immunodeficiency Virus

Received: $28-11-2006$

Accepted: $26-04-2007$

\section{Introduction}

More than twenty years after it was first diagnosed, HIV remains a major global health problem. Sub-Saharan Africa is the region that has been most severely affected by HIV and continues to have the highest prevalence of HIV in the world. ${ }^{1}$ At present there are approximately one million children in Sub-Saharan Africa infected with HIV, this accounts for over $90 \%$ of the HIV infected children in the world. ${ }^{2}$ In Southern Africa HIV related illness has become the leading cause of death in children less than five years of age. ${ }^{3}$ Access to antiretroviral drugs is only starting to be realised for most people in South Africa and other African countries. As more people gain access to antiretroviral therapy we can expect to see the transition of HIV from an acute, terminal disease to a subacute, chronic disease. This has significant implications

\section{Correspondence:}

J Potterton

Department of Physiotherapy, University of the Witwatersrand

7 York Road, Parktown, 2193, Johannesburg, South Africa

email: Joanne.Potterton@wits.ac.za regarding increased psychosocial and rehabilitation needs of this population. ${ }^{4,5}$

Being the parent of any child is inherently stressful to a certain degree. 6,7 Ostburg and Hagekull (2000) investigated the predictors of parenting stress in a population of 1081 Swedish mothers of healthy children. They found that high work load, low social support, perception of the child as 'difficult', negative life events, child caretaking hassles, more children in the family and high maternal age were directly related to increased levels of parenting stress. No buffering effects of social support were found. ${ }^{8}$ Having a child with a disability or a chronic health condition has repeatedly been shown to increase parenting stress. ${ }^{9-14}$ Dyson (2001) examined parental stress and family functioning in families with children with handicaps. She found that parental stress was high and was independent of economic and social constraints and that levels of stress did not affect family functioning. She suggests that to decrease stress, intervention should focus on increasing child competencies, caretaking of the child and changing parental perception of the child as it was these areas which contributed most to parental stress. ${ }^{10}$ A number of studies have 
found that the level of impairment in disabled children was a significant predictor of stress in mothers of children with cerebral palsy.11,15 A study conducted in Malaysia by Ong et al (1991) found that mothers of children with cerebral palsy who had greater care-giving demands and required more frequent hospitalisation were more stressed. Mothers with lower levels of education also experienced more parenting stress in their study. ${ }^{12}$

Poverty has the potential to impact negatively on early childhood development. ${ }^{16-19}$ Emerson (2004) noted that even in developed countries, poverty was associated with poor parental health and well-being and consequently poorer parenting practices and that the experience of poverty is often associated with poor child heath and well-being. ${ }^{20}$ Some authors state that the length of time a child is exposed to poverty is an important factor to take cognisance of ${ }^{21}$, while others argue that the timing of exposure to poverty is also important with children born into a poor household being at greater risk than those exposed to poverty at a later stage of their childhood. ${ }^{22}$ Schor et al (2003) report that parents are central to paediatric care. The health and well-being of children is inextricably linked to their parent's physical, emotional and social health as well as their social circumstances and child rearing practices. There is enormous diversity among families and this impacts on child rearing practices and the way in which families and individual parents respond to stress. Child health is strongly related to family income. ${ }^{18}$

Poverty remains a serious concern in South Africa with the potential to impact negatively on the health and well-being of South African children. Around the world HIV is a disease exacerbated by poverty. The most vulnerable members of a community are hit hardest by this disease. 5,22-24 Children in South Africa are therefore extremely vulnerable as they face exposure to both poverty and HIV.

Paediatric HIV is a multigenerational disease. The diagnosis of a child as HIV positive almost always means that at least the mother, and possibly the father, is infected as well. This makes HIV very different from other chronic childhood diseases. Families affected by HIV are also more likely to be poor and are often inhibited from accessing the services and support which they require due to stigmatisation of HIV, they may also have limited access to health care. Families affected by HIV also experience multiple losses which add to the psychosocial burden and emotional distress experienced by the family. ${ }^{25-28}$

Reidy et al (1991) highlight the fact that children who are HIV positive require nurturing as well as care necessitated by their illness. ${ }^{28}$ This places an increased burden on the primary caregiver of the child, who may themselves be HIV positive. HIV is a progressive chronic illness which requires long term family involvement and commitment. As the disease progresses the child will present with severe acute signs and symptoms which require frequent and intensive medical intervention. Caring for a child with HIV is a time consuming and burdensome activity. Caregivers are beset with constant concerns over the child's health and worries about what the future may hold, they often feel inadequate as they are unable to meet the child's needs and lack confidence in their own parenting abilities. ${ }^{22,28}$ Linsk and Mason (2004) investigated the stresses on grandparents and other relatives caring for children affected by HIV and found that the caregivers infected with HIV themselves experienced the most stress. ${ }^{29}$

DeMarco et al (2002) found that mothers who are HIV positive themselves tend to "silence" their own needs and attend to the needs of their children and others first. ${ }^{30}$ This included physical and health needs as well as psychological needs. This practice of "silencing self" ultimately places an increased burden on the mothers and means that they do not readily seek the help they need even when it is available. Mothers who experienced difficulty in caring for their children due to ill health experienced high levels of psychological disturbance. ${ }^{15}$

Mothers of HIV infected children experience chronic sorrow, from the time of their child's diagnosis and for the rest of the child's life as she faces the challenges and illnesses which paediatric HIV inevitably brings. ${ }^{31}$ A need exists for support groups which address the needs of HIV positive mothers within the context of their family. Mothers who were HIV positive also expressed the need for a "one-stop" clinic where all the health and psychosocial needs of themselves and their children could be met. ${ }^{32,33}$

Parenting stress is a complex issue which is confounded by many psychosocial factors. Caregivers of HIV positive children are at risk of increased levels of parenting stress. The parenting stress of caregivers of HIV positive children in developing countries, who face the additional burden of poverty, has not been fully explored.

The aim of this study was therefore to measure the parenting stress levels of caregivers of young children infected with HIV. Further objectives were to monitor the parenting stress levels over one year after parents started bringing their children to an HIV clinic and to determine what factors were predictive of parenting stress.

\section{Method}

This study was conducted at Chris Hani Baragwanath hospital in the paediatric HIV clinic (Harriet Shezi clinic). One hundred and twenty two consecutive HIV positive children and their primary caregivers were enrolled in this study. Children were under 2.5 years at the start of the study period. Ethical clearance and informed consent were obtained (Human Research Ethics Committee:University of the Witwatersrand) prior to enrolling the children and their caregivers. Attendance at the clinic was monitored and intention to treat analysis was done.

All caregivers completed a demographic questionnaire and the Parenting Stress Index/ Short form. The questionnaires were available in English, Zulu and Sotho. The PSI/SF was translated with permission from the original author and the translations have been shown to have good test retest reliability. The PSI/SF was re-administered after six and 12 months.

At each visit the children's height and weight were recorded and their latest CD4 count was noted in their files.

Data were summarized using means and standard deviations. An appropriate analysis of variance was done to determine the change in parenting stress over the study period. A step wise regression analysis was performed to determine what factors predicted a decrease in parenting stress over the study period.

The Parenting Stress Index (PSI/SF) contains 36 items 
across 3 subscales that are reported to have good reliability. ${ }^{7}$ The 3 subscales are "Parental Distress", "Parent-Child Dysfunctional Interaction" and "Difficult Child". Items are rated on a 5 point scale from "strongly agree to "strongly disagree," with higher scores indicating higher levels of stress. The PSI/SF provides a total stress score as well as 3 sub-scale stress scores. Evidence for test-retest reliability (Pearson correlations of .84 for the total stress scores and .68 to .85 for subscale scores) is given in the test manual. ${ }^{7}$

\section{Results}

The average age of the children at baseline was 18.5 months. There were not that many very young infants in the study. Many of these children are not being diagnosed as HIV positive soon after birth and are only diagnosed once a level of clinical suspicion has warranted further investigation.

The majority of caregivers in this study were the biological mothers of the children (85.25\%). This high proportion of children being cared for by their own mothers is obviously the desired situation. However the children are still very young and many may lose their mothers in time to come. Almost 10\% of children in this study were being cared for by their grandmothers. The needs of grandmothers caring for their HIV infected grandchildren have been explored, however very little has been done in the context of developing countries. ${ }^{18,29,34}$

The mean age of the caregivers in this study was 30.7 years. The majority of the mothers were between the ages of 24 and 34 years. This is the age of young women most vulnerable to HIV infection. ${ }^{2}$

Only one quarter of caregivers had completed school and matriculated. The majority of caregivers had at least a grade nine level of education. While this would ensure basic numeracy and literacy finding stable employment with less than a grade 12 level of education is very difficult. ${ }^{35}$ The demographic information is summarized in Table 1.

The average household composition was 3.2 adults and 3.5 children. Mean monthly income was R1 183. The families in this study were therefore extremely poor.

While $42.6 \%$ of caregivers in this study lived in a brick house not shared with other families, $21.3 \%$ lived in shacks. The remaining families lived in shared brick homes or rented rooms. Those who lived in shacks shared outside toilet facilities with other families and did not have running water in the home. Very few shacks had an electricity supply. The increased burden of caring for a chronically ill child under such difficult circumstances is hard to imagine.

The levels of parenting stress were extremely high at baseline and although they did come down significantly $(p<0.001)$ over the one year study period, they remain clinically significant. A score of 90 or above is considered to indicate the need for clinical intervention. ${ }^{7}$ The parenting

\begin{tabular}{|c|c|}
\hline Age of children (months) & $18.5( \pm 8.1)$ \\
\hline $\begin{array}{l}\text { Primary Caregiver } \\
\text { Mother } \\
\text { Father } \\
\text { Grandmother } \\
\text { Other }\end{array}$ & $\begin{array}{l}104(85.2 \%) \\
2(1.6 \%) \\
11(9 \%) \\
5(4 \%)\end{array}$ \\
\hline Age of Caregiver & $30.8( \pm 9.4)$ \\
\hline $\begin{array}{l}\text { Education caregiver } \\
<\text { Grade } 5 \\
\text { Grade } 5-6 \\
\text { Grade } 7-9 \\
\text { Grade 10-11 } \\
\text { Grade } 12 \\
\text { Tertiary }\end{array}$ & $\begin{array}{l}3(2.5 \%) \\
2(1.6 \%) \\
18(14.7 \%) \\
62(51 \%) \\
32(26.2 \%) \\
5(4 \%)\end{array}$ \\
\hline Number of adults in household & $3.2( \pm 2.0)$ \\
\hline Number of children in household & $3.5( \pm 1.88)$ \\
\hline Monthly income (ZAR) & $\mathrm{R} 1187$ ( \pm 1893) \\
\hline $\begin{array}{l}\text { Housing } \\
\text { Shack } \\
\text { Single room } \\
\text { Flat } \\
\text { Shared house } \\
\text { Own house }\end{array}$ & $\begin{array}{l}26(21 \%) \\
16(13 \%) \\
4(3.2 \%) \\
24(19.7 \%) \\
52(42.6 \%)\end{array}$ \\
\hline $\begin{array}{l}\text { Amenities in home } \\
\text { Fridge } \\
\text { TV } \\
\text { Telephone/cell phone } \\
\text { Car } \\
\text { VCR } \\
\text { Washing machine } \\
\text { Microwave }\end{array}$ & $\begin{array}{l}90(74 \%) \\
92(75.4 \%) \\
78(64 \%) \\
7(5.7 \%) \\
23(18.9 \%) \\
14(11.5 \%) \\
22(18 \%)\end{array}$ \\
\hline
\end{tabular}

stress levels as measured by the PSI/SF at baseline, six months and twelve months are presented in Table 2

The step-wise regression analysis revealed that the three factors which were the most important predictors of a decrease in parenting stress levels were, the educational level of the caregiver, the number of adults in the household and the type of house in which the family lived. A higher level of education was predictive of a decrease in parenting stress. These caregivers may be better able to access the support and information offered to them at Harriet Shezi clinic. The more adults there were in the household the less likely the

Table 2. Parenting stress levels over a one year period

\begin{tabular}{|l|l|l|l|l|}
\hline & Parental dysfunction & Parent-child dysfunctional interaction & Difficult child & PSI/SF Total Stress \\
\hline Baseline $n=122$ & $37.24( \pm 8.4)$ & $32.71( \pm 8.8)$ & $33.93( \pm 7.2)$ & $103.95( \pm 19.5)$ \\
Six months $n=93$ & $35.69( \pm 9.5)$ & $29.65( \pm 8.9)$ & $32.96( \pm 8.6)$ & $98.29( \pm 23)$ \\
Twelve months $n=92$ & $34.42( \pm 9.6)$ & $29.91( \pm 10.1)$ & $33.15( \pm 8.2)$ & $96.66( \pm 22.6)$ \\
\hline
\end{tabular}


parenting stress levels were to come down. The stress of secrecy and stigma may have contributed to this. Living in a flat or their own house was predictive of decreasing parenting stress, however staying in a room or a shared house was predictive of increasing stress levels. The lack of privacy associated with living in a confined space or with other families are possible explanations for this.

\section{Discussion}

The parenting stress levels in the caregivers who participated in this study were extremely high at the baseline assessment (103.95 \pm 19.51$)$. These very high parenting stress levels are of concern as any score over 90 is considered to be clinically significant and to warrant referral for further investigation. ${ }^{7}$ Other studies that have used the PSI/SF with caregivers of disabled children have not documented scores as high as these even though their scores were also elevated. ${ }^{11,36,37}$ Studies that have investigated the stress levels of caregivers of HIV positive children have not made use of the PSI/SF, this makes it difficult to compare levels of parenting stress measured in this study to those found in other studies.

Many studies have shown that having a child with a chronic illness leads to increased levels of parenting stress. ${ }^{6}$ It is not at all surprising that caregivers of children infected with HIV experience such high parenting stress levels. The levels in this study may be particularly high due to the feelings of helplessness that caregivers must experience when they are not able to access optimal care for their children. As access to HAART improves and the overall health status of children and caregivers infected with HIV hopefully improves as well, it would be interesting to see whether the parenting stress levels of these caregivers begins to come down to more clinically acceptable levels.

The multigenerational aspect of HIV sets it apart from most other chronic childhood disabilities. The fact that the mothers in this sample are dealing with their own diagnosis, that of their child, as well as possibly their partner may contribute to their extraordinarily high parenting stress levels. Social support has been shown to be a mediating factor for parenting stress in some ${ }^{8,38,39}$, but not all studies done on parenting children with disabilities. ${ }^{11,40}$ The fact that the caregivers in this study had to deal with the stigma and isolation often associated with HIV diagnosis, as well as extreme poverty, may have made it more difficult for them to access social support. $25,31,32$

The results of the parenting stress of grandparents were not isolated from the overall group due to the fact that the number of caregivers who were not mothers was so small. The needs of grandparents caring for their HIV positive grandchildren must not be overlooked. Grandparents are having to assume financial responsibility for their grandchildren as well becoming their primary caregiver. The physical challenges of caring for a young child again at a time of their lives when their own health care needs are increasing could be placing the health related quality of life of these grandparents in jeopardy. Numerous studies have found that grandparents, like mothers, will place the needs of their children and grandchildren first and are at risk of neglecting their own health. 29,34,37 The health and psychosocial needs of grandmother caregivers should be given particular attention.

The amount of stress experienced by caregivers decreased significantly over the study period. It is important to note that although parenting stress did decrease it remained at levels considered to be clinically significant. Of the three subscales, the Parental Dysfunction and Parent Child Dysfunctional Interaction scores came down significantly over the study period, however there was no significant improvement in the Difficult Child sub-scale scores over time. The parent's perception of their child as being 'difficult' has been shown to be a predictor of increased levels of parenting stress. ${ }^{8}$

Caregivers with higher levels of education, better housing and fewer adults in the household were the ones who were most likely to experience decreased levels of parenting stress after one year. These caregivers were probably better equipped to access the services available to them at the clinic and in their communities. Harriet Shezi Clinic has counselors who are available to discuss issues with the caregivers. Caregivers may also be referred to a social worker, dietician and psychologist. These supportive structures may be responsible for the decrease in parenting stress seen after one year of attending the clinic. These caregivers may also be more financially secure and therefore less vulnerable to the stresses of extreme poverty.

\section{Conclusion}

Caregivers of children who are HIV positive are experiencing clinically significant levels of parenting stress. Additional psychosocial support and possibly formal counseling and psychological services should be made available to these caregivers.

The levels of parenting stress were extremely high in this group of caregivers. Although the PSI/SF scores did come down significantly over the study period they remained clinically significant. Further research is needed to explore in more detail the factors that contribute to such high parenting stress levels and to start to investigate how best to address this problem in this population of caregivers.

\section{References}

1. Lau C,, Muula A. HIVIAIDS in Sub-Saharan Africa. Croatian Medical Journal 2004; 45(4): 402-414

2. UNAIDS 2005 Report on the global HIVIAIDS epidemic.

3. Brown L, Lourie K, Maryland P. Children and Adolescents Living with HIV and AIDS: A Review. Journal of Child Psychology and Psychiatry 2000; $41(1): 81-96$

4. Nixon S, Cott C. Shifting Perspectives: reconceptualising HIV disease in a rehabilitation framework. Physiotherapy Canada Summer 2000; 189-197

5. Bachanas P, Kullgren K, Suzman Schwartz K, McDaniel J, Smith J, Nesheim S. Psychological Adjustment in Caregivers of School-Age Children Infected with HIV: Stress, Coping and Family Factors. Journal of Pediatric Psychology 2001;26(6): 331-342

6. Deater-Deckard K, Scarr S. Parenting stress among dual-earner mothers and fathers: Are there gender differences? Journal of Family Psychology 1996;10(1): 45-59

7. Abidin R. Parenting Stress Index Professional Manual. Third Edition. Psychological Assessment Resources, Inc, 1995

8. Ostberg M, Hagekull B. A Structural Modelling Approach to the Understanding of Parenting Stress. Journal of Clinical Child Psychology 2000; 29(4): 615-625

9. Esdaile S, Greenwood K. A Comparison of Mother's and Father's Experience of Parenting Stress and Attributions for Parent-child 
Interaction Outcomes. Occupational Therapy International 2003;10(2): 115-126

10. Dyson L. Families of Young Children with Handicaps: Parental Stress and Family Functioning. American Journal on Mental Retardation 1991; 95(6): 623-629

11. Button S, Pianta R, Marvin R. Partner support and maternal stress in families raising young children with cerebral palsy. Journal of Developmental and Physical Disabilities 2001;13(1):61-81

12. Ong L, Afifah I, Sofiah A, Lye M. Parenting stress among mothers of Malasian children with cerebral palsy: predictors of child- and parent-related stress. Annals of Tropical Paediatrics 1998;18: 301307

13. Bithoney W, van Sciver M, Foster S, Corso S, Tentindo C. Parental stress and growth outcome in growth-deficient children. Pediatrics 1995; 96(4): 707-711

14. Ultmann $M$, Belman A, Ruff $H$, Novick B, Cone-Wesson B, Cohen $H$, Rubinstein A, Trute B, Hiebert-Murphy D. Family Adjustment to Childhood Developmental Disability: A Measure of Parent Appraisal of Family Impacts. Journal of Pediatric Psychology 2002; 27(3): 271 280

15. Silver E, Westbrook L, Stein R. Relationship of Parental Psychological Distress to Consequences of Chronic Health Conditions in Children. Journal of Pediatric Psycholgy 1998; 23(1): 5-15

16. Catherwood D. New Views on the Young Brain: offerings from developmental psychology to early childhood education. Contemporary Issues in Early Childhood $1999 ; 1$ (1):23-35

17. Linver M, Brooks-Gunn J, Kohen D. Family Processes as Pathways From Income to Young Children's Development. Developmental Psychology 2002; 38(5): 719-734

18. Schor E, Billingsley M, Golden A, McMillan J, Meloy L, Pendarvis B. Family Pediatrics: Report of the Task Force on the Family. Pediatrics 2003;111(6): 1541-1571

19. Lima M, Eickmann S, Lima A, Guerra M, Lira P, Huttly S, Ashworth A Determinants of mental and motor development at 12 months in a low income population: a cohort study in Northeast Brazil. Acta Paediatrica 2004; 93: 969-975

20. Emerson E. Poverty and children with intellectual disabilities in the world's richer countries. Journal of Intellectual and Developmental Disability 2004; 29(4): 319-338

21. Duncan G, Brookes-Gunn J, Klebanov P. Economic Deprivation and Early Childhood Development. Child Development 1994; 65: 296318

22. Adler R. Psychosocial Issues in Pediatric Human Immunodeficiency Virus. Seminars in Speech and Language 2000; 21 (1): 79-87

23. Foster G, Williamson J.A Review of Current Literature on the Impact of HIVIAids on Children in Sub-Saharan Africa. AIDS 2000; 14(suppl3): S275-S284

24. Dutra R, Forehand R, Armistead L, Brody G, Morse E, Morse P, Clark
L. Child resiliency in inner-city families affected by HIV: the role of family variables. Behaviour Research and Therapy 2000; 38: 471-486

25. Orner P. Psychosocial impacts on caregivers of people living with AIDS. AIDS Care $2006 ; 18(3):$ 236-240

26. Katapa R S. Caretakers of AIDS patients in rural Tanzania. International Journal of STD and AIDS 2004;15: 673-678

27. Lewis S, Wesley Y, Haiken H. Pediatric and Family HIV Psychosocial concerns across the continuum of the disease. Nursing Clinics of North America 1996; 31 (1): 221-230

28. Reidy M, Taggart M-E, Asselin L. Psychosocial needs expressed by the natural caregivers of HIV infected children. AIDS Care 1991;3(3): $331-343$

29. Linsk N, Mason S. Stress on Grandparents and other relatives Caring for Children Affected by HIVIAIDS. Health and Social Work 2004; 29(2): 127-136

30. DeMarco R, Lynch M, Board R. Mothers Who Silence Themselves: A Concept with Clinical Implications for Women Living with HIVIAIDS and their Children. Journal of Pediatric Nursing 2002; 17(2):89-95

31. Antle B, Wells L, Goldie R, DeMatteo D, King S. Challenges of Parenting for Families Living with HIVIAIDS. Social Work 2001; 46(2): 159-169

32. Hackl K, Somlai A, Kelly J, Kalichman S. Women Living with HIVIAIDS: The dual challenge of being a patient and a caregiver. Health and Social Work 1997; 22(1): 53-62

33. Marcenko M, Samost L. Living with HIVIAIDS: The Voices of HIVPositive Mothers. Social Work 1999; 44(1): 36-45

34. Joslin D, Harrison R. The "Hidden Patient": Older Relatives Raising Children Orphaned by AIDS. JAMWA 1998; 53(2): 65-71

35. Barbarin O, Khomo N. Indicators of Economic Status and Social Capital in South African Township.s. Childhood 1997; 4(2): 193-222

36. O'Neil M, Palisano R, Westcott S. Relationship of therapists' attitudes, children's motor ability, and parenting stress to mothers' perceptions of therapists' behaviors during early intervention. Physical Therapy 2001; 81(8): 1412-1424

37. Musil C. Health, Stress, Coping and Social Support in Grandmother Caregivers. Health Care Women International 1998; 19: 441-455

38. Raina P, O'Donnell M, Schwellnus H, Rosenbaum P, King G, Brehaut J, Russell D, Swinton M, King S, Wong M, Walter S, Wood E. Caregiving process and caregiver burden: Conceptual models to guide research and practice. BMC Pediatrics 2004; 4:1 doi:10.1186/14712431-4-1 http://www.biomedcentral.com/1471-2431/4/1

39. McKinney B, Peterson R. Predictors of Stress in Parents of Developmentally Disabled Children. Journal of Pediatric Psychology 1987; 12(1): 133-150

40. Hansell P, Hughes C, Calliandro G, Russo P, Budin W, Hartman B, Hernandez O. The Effect of a Social Support Boosting Intervention on Stress, Coping and Social Support in Caregivers of Children with HIVIAIDS. Nursing Research 1998; 47(2): 79-86 